\title{
Nonsmokers' responses to new warning labels on smokeless tobacco and electronic cigarettes: an experimental study
}

\author{
Lucy Popova ${ }^{1 *}$ and Pamela M Ling ${ }^{1,2}$
}

\begin{abstract}
Background: Graphic warning labels are a tobacco control best practice that is mandated in the US for cigarettes under the 2009 Family Smoking Prevention and Tobacco Control Act. However, smokeless tobacco products are not required to carry graphic warning labels, and as of September 2014, electronic cigarettes in the US carry no warning labels and are aggressively marketed, including with "reduced harm" or "FDA Approved" messages.
\end{abstract}

Methods: In this online experiment, 483 US adult non-users of tobacco were randomized to view print advertisements for moist snuff, snus, and e-cigarettes with either warning labels (current warning label, graphic warning label) or "endorsements" (a "lower risk" label proposed by a tobacco company, an "FDA Approved" label) or control (tobacco advertisement with no label, advertisement for a non-tobacco consumer products). Main outcome measures included changes in perceived harm, positive attitudes towards, openness to using, and interest in a free sample of moist snuff, snus, and e-cigarettes.

Results: The graphic warning label increased perceived harm of moist snuff and e-cigarettes. "Lower risk" and "FDA Approved" labels decreased perceived harm of moist snuff and snus respectively. Current warning label and graphic warning label significantly lowered positive attitudes towards e-cigarettes. In this sample of non-users of tobacco, 15\% were interested in a free sample of alternative tobacco products (predominantly e-cigarettes). Proportion of participants interested in a free sample did not differ significantly across the conditions, but those interested in a free sample had significantly lower perceptions of harm of corresponding tobacco products.

Conclusions: Regulatory agencies should not allow "lower risk" warning labels, which have similar effects to the "FDA Approved" label, which is prohibited, and should consider implementing graphic warning labels for smokeless tobacco products and e-cigarettes.

Keywords: Tobacco, Smokeless tobacco, Electronic cigarette, Warning labels, Snus

\section{Background}

Tobacco use remains the leading cause of preventable death in the United States [1]. Risks of tobacco use have been identified [2], and understanding of these risks is one of the main factors that explains initiation and cessation of tobacco use [3-7].

One of the central approaches to increasing perceived risk of tobacco products has been the use of warning

\footnotetext{
* Correspondence: lyudmila.popova@ucsf.edu

${ }^{1}$ Center for Tobacco Control Research and Education, University of California San Francisco, 530 Parnassus Avenue, Suite 366, San Francisco, CA 94143, USA Full list of author information is available at the end of the article
}

labels [8]. Most research to date has focused on cigarette warning labels, specifically graphic warning labels, which have been mandated by law in 63 countries globally [9]. Graphic warning labels promote cessation behavior $[10,11]$ and are effective in communicating the harm of cigarettes [8]. In the US, in 2009 the Family Smoking Prevention and Tobacco Control Act mandated the Food and Drug Administration (FDA) to implement graphic warning labels on cigarettes, bringing the US closer in alignment to the World Health Organization's Framework Convention on Tobacco Control (FCTC) [12] and the European Commission's Tobacco Product Directive [13], both of which 
recommend large pictorial health warnings. The proposed US graphic warning labels would cover top 50\% of both front and back of cigarette packages, which is consistent with WHO FCTC recommendation of $50 \%$ or more of the principal display areas [12], but is less than the recently revised European Commission's Tobacco Product Directive (65\% of the front and back of the cigarette pack) [13].

In addition, new warning labels may be developed for tobacco products other than cigarettes. In recent years, tobacco and e-cigarette companies have been aggressively developing and promoting new alternative tobacco products, such as electronic cigarettes (e-cigarettes), snus, and dissolvable tobacco products [14-17]. E-cigarettes are electronic devices generally consisting of a battery connected to a heater, a mouthpiece, and a chamber containing a solution of propylene glycol and other chemicals, frequently including nicotine. When the device is used, the solution is vaporized by the heater, producing an aerosol that is inhaled. Snus is ground tobacco placed in a porous pouch to be placed between lip and gum to allow nicotine absorption; snus sold in the US is modeled after a traditional Swedish product which typically is manufactured so that it contains fewer tobaccospecific nitrosamines (carcinogens) than other forms of chewing tobacco [18].

Currently, some of these products (smokeless tobacco) carry warning labels, and others (e-cigarettes) do not. While graphic warning labels have been mandated by law for cigarettes, they have not been established for alternative tobacco products, and research on the effects of graphic warning labels on smokeless tobacco is nascent [19]. There is no research on the effects of warning labels on e-cigarettes, and the current marketing frequently refers to reduced risk. A systematic content analysis of electronic cigarette websites found $95 \%$ of websites made health related claims, such as the statement, "Can't argue with 4,000 less chemicals!" [20]. While it has been suggested that e-cigarettes should be promoted as "reduced harm" alternatives to combustible cigarettes for smokers [21], there are no long term data on the health effects of e-cigarette use, and widespread promotion may also result in uptake among non-users of tobacco, which would be inconsistent with harm reduction on a population level [22]. Warning labels on e-cigarettes might discourage people who do not use tobacco from starting. We investigated the effects of placing warning labels on ecigarette advertising on perceived harm of e-cigarettes among non-users, hypothesizing that any warning label will increase perceptions of harm of e-cigarettes.

Since 1998, marketing expenditures for smokeless tobacco have increased by $277 \%$ [23]. Since 2009, cigarette companies have purchased smokeless tobacco companies, and now sell both traditional and novel smokeless tobacco products, which are frequently promoted for temporary use in smoke-free environments [14]. In the United States, smokeless tobacco products (moist snuff, snus, dissolvables) currently display one of four text warning labels mandated for smokeless tobacco products:

\section{"WARNING: This product can cause mouth cancer." \\ "WARNING: This product can cause gum disease and tooth loss."}

"WARNING: This product is not a safe alternative to cigarettes."

"WARNING: Smokeless tobacco is addictive."

In 2011, R. J. Reynolds Tobacco Company submitted a Citizen Petition to the US Food and Drug Administration requesting to change one of the smokeless tobacco warning labels from "WARNING: This product is not a safe alternative to cigarettes" to "WARNING: No tobacco product is safe, but this product presents substantially lower risks to health than cigarettes" [24], linking the warning statement to an implicit endorsement.

In addition, there have been longstanding concerns that tobacco companies might try to use FDA regulation (and their compliance with it) as a marketing strategy and promote new tobacco products as meeting the FDA requirements or being "FDA Approved". Although the Family Smoking Prevention and Tobacco Control Act explicitly prohibits use of "FDA Approved" language for marketing of tobacco products, this restriction currently does not apply to e-cigarettes, which are sometimes advertised as "made in an FDA Approved facility" [25-28]. The "endorsement" label proposed by R. J. Reynolds may also be interpreted like an "FDA Approved" label.

To our knowledge, there are currently no studies on the effect of communicating FDA oversight of tobacco on consumer perceptions of harm of new tobacco products. The R. J. Reynolds' proposed "endorsement" label has not been studied empirically, and it might act equivalently to an "FDA Approved" endorsement. This study compared the label proposed by R. J. Reynolds to a label stating the product is "FDA Approved". We hypothesized that exposure to either of the reduced harm messages would decrease perceived harm of alternative tobacco products, and that the R. J. Reynolds label would have an effect similar to the "FDA Approved" label.

\section{Methods}

\section{Participants}

Participants were 506 non-users of tobacco recruited by Toluna (www.toluna-group.com), a survey and market research company, to complete a single online experiment. Participants were recruited through a variety of 
online and offline recruitment strategies and responded to surveys in exchange for cash rewards provided by Toluna. The sample was screened to include only adults aged 18+ who were not established tobacco users, (e.g., they had not smoked 100 cigarettes in their entire life, and had not used smokeless tobacco such as chewing tobacco, snuff, dip, or snus at least 20 times in their entire life). Participants who reported current (past 30 day) use of any alternative tobacco products $(n=23)$ were excluded from further analyses in order to focus on non-users of tobacco. Thus, the final sample included 483 non-users of tobacco. Among them, $4 \%$ had ever tried one of the new and alternative tobacco products, but not in the past month.

To ensure eligibility of participants, participants had to enter their zip code in the beginning and end of the survey; those whose zip codes did not match had their session terminated. Additional procedures for data quality control are described at http://www.toluna-group.com/about-toluna/ about/data-quality-approach. All participants completed electronic informed consent forms and all protocols were approved by the Committee on Human Research (the IRB) at the University of California San Francisco.

\section{Procedure}

The experimental procedure is illustrated in Figure 1. Participants began by filling out a pretest questionnaire comprising demographic questions, measures of past tobacco use and outcome variables (perceived harm, positive attitudes, and openness to using moist snuff, snus, and e-cigarettes). They were then randomized to one of six groups: five groups saw advertisements for alternative tobacco products with either a warning: 1) current warning label, "Warning: This product is not a safe alternative to cigarettes" (this warning is currently mandated for smokeless tobacco), 2) graphic warning label (picture of a mouth sore and words "Warning: This product can cause mouth cancer;" an endorsement: 3) R. J. Reynolds's proposed "lower risk" label, "Warning: No tobacco product is safe, but this product presents substantially lower risks to health than cigarettes," 4) "FDA Approved" label; 5) an advertisement for a tobacco product with no warning label, or 6) a control group that saw advertisements for a non-tobacco consumer products (such as a cell phone or gum) (Figure 1). While the "FDA Approved" label is prohibited for tobacco products currently regulated

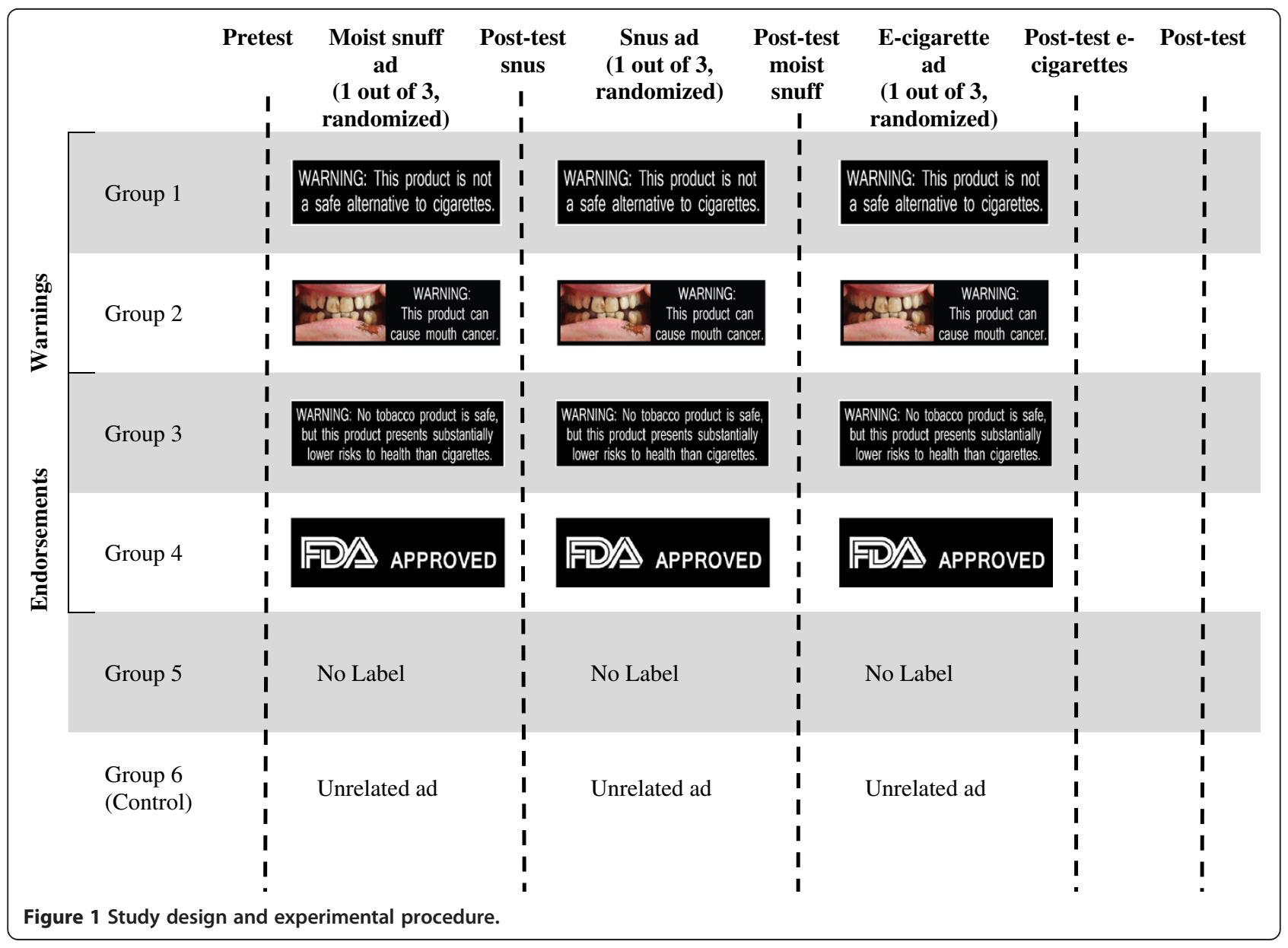


by the FDA, this condition was used to facilitate comparison to the prohibited message. In each experimental condition, participants saw advertisements for three products (presented in random order to mitigate order effects): moist snuff, snus, and e-cigarettes. For each product, the advertisement shown was randomly drawn from three advertisements for each type of alternative tobacco products. Warning labels were added to the bottom of each advertisement to cover $20 \%$ of the total area of the advertisement as required by law for smokeless tobacco warnings [29]. Following exposure to each advertisement, participants completed outcome measures (perceived harm, attitudes, and intentions to use this product) in a posttest. Median time to complete the study was 12 minutes.

\section{Measures}

\section{Demographics and tobacco use}

Demographic variables included sex, age, race, annual household income, educational level, and geographical region. Ever and current (past 30 days) use of alternative tobacco products was measured for each of five alternative tobacco products: loose leaf, moist snuff, snus, dissolvables, and electronic cigarettes.

\section{Outcome variables}

Perceived harm of tobacco products was measured with two questions: 'In your opinion, how harmful is ... (moist snuff, snus, e-cigarettes) to general health?' and 'In your opinion, to what extent does ... cause cancer?' reported on 9-point Likert scales ranging from 'Not at all' to 'Extremely.' The answers to the two questions were averaged to create a perceived harm scale (Cronbach's alphas 0.950.98 ) for each of the three products. The positive attitudes scales comprised four items measured on a 9-point semantic differential scales: "Using (moist snuff, snus, e-cigarettes) is: good-bad, intelligent-unintelligent, appropriate-not appropriate, and pleasant-unpleasant" with higher scores indicating more positive attitudes (Cronbach's alphas 0.96-0.98). The answers to four questions were averaged. Openness to trying each of the alternative tobacco products was measured with one item, "How open are you to trying ... (moist snuff, snus, e-cigarettes) in the future?" with answers on 9-point Likert scales ranging from 'Not at all open' to 'Extremely open'.

\section{Behavioral task - selection of free sample of alternative tobacco products}

After the exposure to each advertisement, participants were offered a free sample of alternative tobacco products and asked to select the brand and flavor. After seeing a moist snuff advertisement, participants could choose among Copenhagen, Grizzly, or Skoal moist snuff. After seeing a snus advertisement, participants could choose among Camel snus, Marlboro snus, and General snus, and after seeing an e-cigarette advertisement, they could choose among blu, V2, or NJOY e-cigarette. In every case, they could also select "Not interested in a free sample" option. In the end of the study, the participants were informed that no samples would actually be mailed to them and that this study did not endorse or promote tobacco use in any way. This behavioral selection task has been used in prior studies [30,31].

All products in the same experimental condition bore the same warning label. In the end, participants were asked to select which warning label they saw on the advertisements, with choices being "No warning labels", the text for the four labels (warnings and endorsements) used in the study, and two additional smokeless tobacco warning labels.

\section{Statistical analyses}

All analyses were conducted in IBM SPSS version 21. To examine the effects of individual warning labels on changes in perceived harm we used general linear models (GLM) with time as within-subject factor and warning label condition as between-subject factor. Interactions between time and condition were examined to determine whether any significant omnibus differences over time by condition were present. In addition, we explored pre-post differences within each condition in order to determine which conditions exhibited the strongest differences between the pretest and posttest measurements. Multiple paired comparisons of cell means featured $p$-value adjustment via Tukey's honestly significant difference (HSD) procedure to maintain a nominal alpha of .05 .

\section{Results}

\section{Description of the sample}

The national sample of 483 non-users of tobacco was $44.1 \%$ male, mean age was 47 years. There were no significant differences in participant characteristics between experimental conditions (Table 1). Levels of outcome variables (perceived harm, attitudes, and openness to using moist snuff, snus, and e-cigarettes) measured at pretest are presented in Table 2.

There were no significant differences on the levels of outcome variables at pretest based on gender, age, education, income, and geographical region, with the following exceptions. Women perceived e-cigarettes as more harmful than men did (5.2 vs. $4.5, t(450)=2.60, p<.05)$. Among age groups, 18-29 year olds were significantly more open to trying e-cigarettes in the future than those 60 years old or older $(1.66$ vs. $1.08, F(3,468)=$ $4.02, p<.01)$. In terms of geographical region, participants from the West perceived e-cigarettes as significantly more harmful than did participants from the Northeast (5.57 vs. $4.17, F(3,476)=4.23, p<.01)$. 
Table 1 Participant demographic characteristics for the total sample and for each (randomly assigned) experimental group

\begin{tabular}{|c|c|c|c|c|c|c|c|c|}
\hline Characteristic & $\mathrm{N}$ & $\%$ & $\begin{array}{c}\text { No warning } \\
\text { label }(n=75), \%\end{array}$ & $\begin{array}{l}\text { Current warning } \\
\text { label }(n=74), \%\end{array}$ & $\begin{array}{l}\text { Lower risks } \\
\text { warning label } \\
(n=75), \%\end{array}$ & $\begin{array}{c}\text { FDA approved } \\
\text { warning label } \\
(n=79), \%\end{array}$ & $\begin{array}{l}\text { Graphic warning } \\
\text { label }(n=76), \%\end{array}$ & $\begin{array}{c}\text { Control } \\
(n=76), \%\end{array}$ \\
\hline \multicolumn{9}{|l|}{ Gender } \\
\hline Male & 206 & 44.1 & 45.0 & 38.5 & 39.2 & 48.8 & 50.0 & 42.5 \\
\hline Female & 249 & 55.9 & 55.0 & 61.5 & 60.8 & 51.2 & 50.0 & 57.5 \\
\hline \multicolumn{9}{|l|}{ Age, years } \\
\hline $18-29$ & 70 & 17.2 & 13.8 & 16.7 & 15.2 & 22.6 & 15.9 & 18.8 \\
\hline $30-44$ & 127 & 27.3 & 31.3 & 32.1 & 27.8 & 20.2 & 29.3 & 23.8 \\
\hline $45-59$ & 134 & 28.8 & 28.7 & 19.2 & 32.9 & 27.4 & 26.8 & 37.5 \\
\hline $60+$ & 124 & 26.7 & 26.3 & 32.1 & 24.1 & 29.8 & 28.0 & 20.0 \\
\hline \multicolumn{9}{|l|}{ Race } \\
\hline White & 232 & 53.0 & 55.0 & 46.2 & 57.0 & 57.1 & 53.7 & 48.8 \\
\hline Black or African American & 94 & 20.1 & 13.8 & 25.6 & 24.1 & 14.3 & 20.7 & 22.5 \\
\hline $\begin{array}{l}\text { American Indian or Alaska } \\
\text { Native }\end{array}$ & 12 & 2.7 & 3.8 & 3.8 & 2.5 & 2.4 & 1.2 & 2.5 \\
\hline Asian & 91 & 18.6 & 23.8 & 16.7 & 12.7 & 19.0 & 19.5 & 20.0 \\
\hline $\begin{array}{l}\text { Native Hawaiian or Pacific } \\
\text { Islander }\end{array}$ & 3 & 0.8 & 0.0 & 2.6 & 0.0 & 1.2 & 1.2 & 0.0 \\
\hline Multiple Races & 21 & 4.3 & 2.5 & 5.1 & 3.8 & 6.0 & 3.7 & 5.0 \\
\hline Unknown & 2 & 0.4 & 1.3 & 0.0 & 0.0 & 0.0 & 0.0 & 1.3 \\
\hline \multicolumn{9}{|l|}{ Education } \\
\hline High school or less & 81 & 19.7 & 15.0 & 20.5 & 21.5 & 16.7 & 20.7 & 23.8 \\
\hline Some college & 91 & 21.9 & 22.5 & 20.5 & 21.5 & 25.0 & 24.4 & 17.5 \\
\hline Bachelor's degree or higher & 283 & 58.4 & 62.5 & 59.0 & 57.0 & 58.3 & 54.9 & 58.8 \\
\hline \multicolumn{9}{|c|}{ Annual Household Income (thousand USD) } \\
\hline$<25$ & 109 & 24.6 & 28.7 & 33.3 & 19.0 & 25.0 & 19.5 & 22.5 \\
\hline $25-59.9$ & 181 & 40.0 & 40.0 & 32.1 & 41.8 & 39.3 & 47.6 & 38.8 \\
\hline$>60$ & 165 & 35.4 & 31.3 & 34.6 & 39.2 & 35.7 & 32.9 & 38.8 \\
\hline \multicolumn{9}{|l|}{ Region } \\
\hline Northeast & 76 & 16.4 & 18.8 & 12.8 & 19.0 & 14.3 & 13.4 & 20.0 \\
\hline Midwest & 90 & 20.5 & 20.0 & 25.6 & 26.6 & 20.2 & 18.3 & 12.5 \\
\hline South & 172 & 37.5 & 37.5 & 33.3 & 29.1 & 46.4 & 41.5 & 36.3 \\
\hline West & 117 & 25.7 & 23.8 & 28.2 & 25.3 & 19.0 & 26.8 & 31.3 \\
\hline
\end{tabular}

Note: No significant differences were found between conditions on participant characteristics.

Table 2 Mean (SD) levels of perceived harm, positive attitudes, and openness to trying alternative tobacco products at pretest

\begin{tabular}{lccc}
\hline & $\begin{array}{c}\text { Perceived } \\
\text { harm }\end{array}$ & $\begin{array}{c}\text { Positive } \\
\text { attitudes }\end{array}$ & $\begin{array}{c}\text { Openness } \\
\text { to trying }\end{array}$ \\
\hline Moist snuff & $7.13(2.59)$ & $1.72(1.50)$ & $1.08(0.57)$ \\
Snus & $7.35(2.13)$ & $1.88(1.62)$ & $1.08(0.50)$ \\
E-cigarettes & $4.91(2.82)$ & $3.47(2.59)$ & $1.34(1.20)$ \\
\hline
\end{tabular}

Note: All measures were on 1-9 scales with higher scores indicating greater perceived harm, more positive attitudes, and greater openness to using the product.
Effect of warning labels on changes in perceived harm The GLM analyses on the effects of warning labels on changes in perceived harm for different tobacco products revealed significant time by group interactions for moist snuff $(F(5,473)=2.54, p<.05)$ and e-cigarettes $(F(5,474)=3.38, p<.01)$. There was no significant time by group interaction for snus $(F(5,471)=0.49, p=.78)$.

Table 3 presents the differences in perceived harm from pretest to posttest. Seeing the advertisements with the current warning label increased perceived harm of ecigarettes $(d=24)$. Exposure to graphic warning labels increased perceived harm of moist snuff $(d=0.27)$ and 
Table 3 Effect of different warning labels and endorsements on perceived harm of tobacco products

\begin{tabular}{|c|c|c|c|c|c|c|c|c|c|}
\hline & \multicolumn{3}{|c|}{ Moist snuff } & \multicolumn{3}{|c|}{ Snus } & \multicolumn{3}{|c|}{ E-cigarettes } \\
\hline & Pretest & Posttest & d & Pretest & Posttest & d & Pretest & Posttest & d \\
\hline Current WL & 7.08 & 7.26 & 0.10 & 7.29 & 7.16 & -0.09 & 5.51 & 5.96 & $0.24^{*}$ \\
\hline Graphic WL & 6.86 & 7.57 & $0.27^{*}$ & 7.54 & 7.56 & 0.01 & 4.33 & 5.67 & $0.54^{*}$ \\
\hline "Lower risks" & 7.47 & 6.96 & $-0.24^{*}$ & 7.13 & 6.89 & -0.12 & 4.81 & 5.15 & 0.15 \\
\hline "FDA Approved" & 7.30 & 7.45 & 0.07 & 7.44 & 6.98 & $-0.25^{*}$ & 5.15 & 5.24 & 0.04 \\
\hline No Label & 7.26 & 7.59 & 0.13 & 7.32 & 7.20 & -0.05 & 5.08 & 5.20 & 0.05 \\
\hline Control Advertisement & 6.78 & 7.31 & 0.20 & 7.37 & 7.27 & -0.04 & 4.56 & 4.94 & 0.19 \\
\hline
\end{tabular}

${ }^{*} p<.05$ (Significant differences from pretest to posttest, multivariate simple effects of time based on the linearly independent pairwise comparisons among the estimated marginal means).

e-cigarettes $(d=0.54)$. Seeing the advertisement with "lower risk" label significantly lowered perceived harm of moist snuff $(d=-0.24)$ and the "FDA Approved" label decreased perceived risk of snus $(d=-0.25)$. The changes in perceived harm are represented graphically in Figure 2.

\section{Effect of warning labels on changes in positive attitudes towards alternative tobacco products}

The GLM analyses for the effects of various labels on changes in positive attitudes towards alternative tobacco products showed no significant time by condition interactions for all three products: moist snuff $(F(5,465)=.402$, $p=.85)$, snus $(F(5,464)=.285, p=.92)$, and e-cigarettes $(F(5,467)=.736, p=.58)$.

For specific conditions (Table 4 ), advertisements with current warning label $(d=-0.28)$ or graphic warning label $(d=-0.26)$ decreased positive attitudes towards e-cigarettes significantly (this is a desired effect).
Effect of warning labels on changes in openness to trying alternative tobacco products

For openness to trying alternative tobacco products, there were no significant time by condition interactions for all three product: moist snuff $(F(5,462)=1.84, p=.10)$, snus $(F(5,459)$ $=1.40, p=.22)$, and e-cigarettes $(F(5,462)=1.57, p=.17)$.

Openness to trying moist snuff went up in every condition (including control) with the exception of "lower risk" and no label condition where increases were not statistically significant (Table 5). For snus, openness increased in all but "lower risk" condition. For e-cigarettes, openness significantly increased in every condition except the graphic warning label and "FDA-approved" conditions.

\section{Behavioral sample selection}

Overall, 14.9\% (71) of participants were interested in receiving a free sample of alternative tobacco products, specifically, moist snuff (5.5\%), snus (7.5\%), and e-cigarettes (13.9\%).

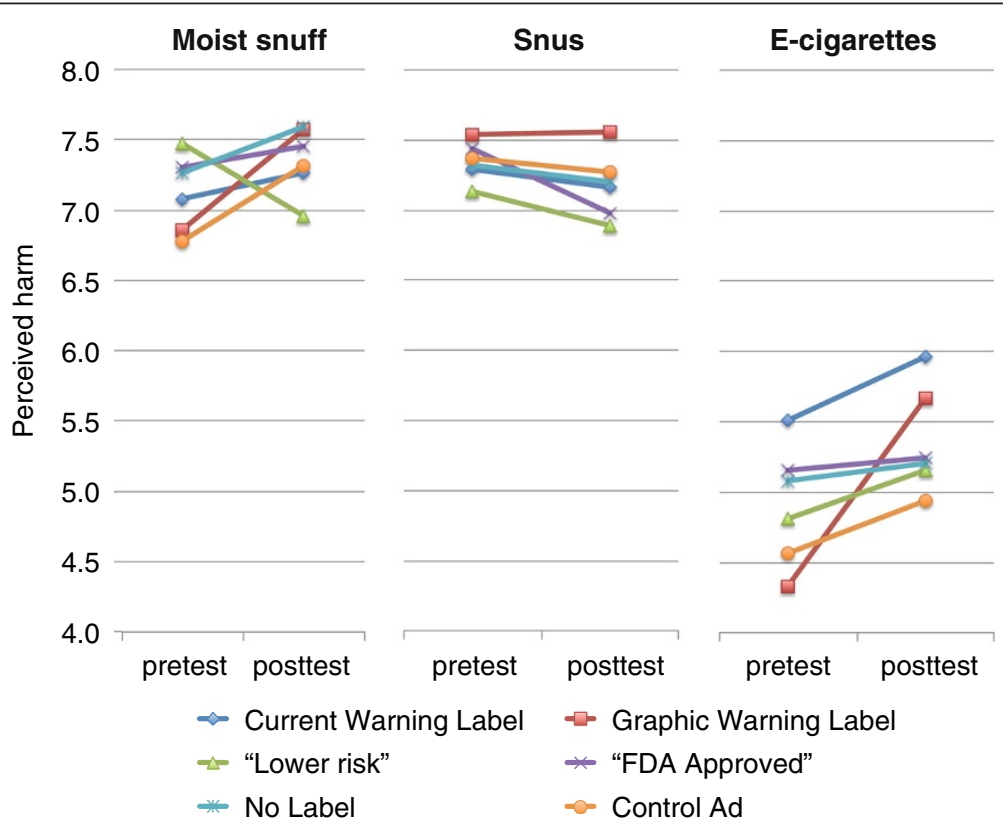

Figure $\mathbf{2}$ Changes in perceived harm from pretest to posttest for cigarettes, snus, electronic cigarettes and moist snuff by warning label condition. Note: Perceived harm was measured on a 9-point scale, with answers ranging from 1 - Not at all harmful to 9 - Extremely harmful. 
Table 4 Effect of different warning labels and endorsements on positive attitudes towards alternative tobacco products

\begin{tabular}{|c|c|c|c|c|c|c|c|c|c|}
\hline & \multicolumn{3}{|c|}{ Moist snuff } & \multicolumn{3}{|c|}{ Snus } & \multicolumn{3}{|c|}{ E-cigarettes } \\
\hline & Pretest & Posttest & d & Pretest & Posttest & d & Pretest & Posttest & d \\
\hline Current WL & 1.90 & 1.88 & -0.02 & 1.93 & 2.02 & 0.07 & 3.06 & 2.67 & $-0.28^{*}$ \\
\hline Graphic WL & 1.77 & 1.74 & -0.03 & 1.84 & 1.85 & 0.00 & 3.48 & 3.02 & $-0.26^{*}$ \\
\hline "Lower risks" & 1.76 & 1.72 & -0.04 & 2.05 & 2.03 & -0.03 & 3.68 & 3.56 & -0.09 \\
\hline "FDA Approved" & 1.75 & 1.60 & -0.18 & 1.87 & 2.04 & 0.12 & 3.44 & 3.14 & -0.20 \\
\hline No Label & 1.45 & 1.51 & 0.09 & 1.72 & 1.76 & 0.03 & 3.39 & 3.11 & -0.15 \\
\hline Control Advertisement & 1.67 & 1.69 & 0.01 & 1.88 & 1.83 & -0.03 & 3.78 & 3.69 & -0.07 \\
\hline
\end{tabular}

${ }^{*} p<.05$ (Significant differences from pretest to posttest, multivariate simple effects of time based on the linearly independent pairwise comparisons among the estimated marginal means).

There were no significant differences across conditions in the proportion of people interested in a free sample $\left(\chi^{2}(5)=\right.$ $1.95, p=.85)$. People who were interested in receiving a free sample of alternative tobacco products had significantly lower perceptions of harm of corresponding tobacco products (measured at posttest) than those not interested in a free sample. Specifically, those interested in a free sample of moist snuff (Mint) had lower perceived harm of moist snuff (Mint $=6.4)$ compared to those not interested (Mnot $=7.4 ; t$ $(472)=2.37, p<.05)$, for snus, Mint $=6.1$ vs. Mnot $=7.2$ $(t(463)=2.74, p<.01)$, and for e-cigarettes $M$ int $=3.8$ vs. $M$ not $=5.6(t(97.3)=5.79, p<.001)$. Unequal variance $t$-tests were used for e-cigarettes [32].

\section{Recall of warning labels}

Correct recall of warning label differed by condition $\left(x^{2}\right.$ $(5)=33.48, p<.001)$, the highest recall being in "lower risks" $(83.5 \%)$ and graphic warning label $(80.2 \%)$ conditions, followed by control (correct recall of no warning label, 78.7\%), then by current warning label (75.3\%), "FDA Approved" (64.3\%), and no warning label (47.1\%). Only $2.5 \%$ of participants indicated seeing labels that were not used in the study.

\section{Discussion}

To our knowledge, this research is the first to examine effects of an "FDA Approved" label and "lower risk" label for alternative tobacco products. Seeing advertisements with "FDA Approved" label significantly decreased perceived harm of snus among non-users of tobacco. Seeing advertisements with a "lower risk" warning label proposed by the R.J. Reynolds tobacco company ("Warning: No tobacco product is safe, but this product presents substantially lower risks to health than cigarettes") significantly decreased perceived harm of moist snuff, the traditional smokeless tobacco product. This suggests that the endorsement label suggested by R.J. Reynolds may function similarly to the "FDA Approved" label, which is prohibited, decreasing perceived harm of tobacco products. Research using previously secret internal tobacco industry documents revealed that some tobacco companies have supported governmental regulation of tobacco as a strategy to improve their public image [33]. In doing so, tobacco companies framed tobacco use as an individual choice and portrayed themselves as responsible manufacturers of risky products [34]. The fact that the new warning label for smokeless tobacco proposed by R. J. Reynolds lowered perceptions of harm of moist snuff among non-users of tobacco indicates that this warning label applied to traditional smokeless tobacco (which has a relatively high level of perceived harm to begin with) can significantly lower perceptions of harm. Some argue that depicting smokeless and alternative tobacco products as less harmful

Table 5 Effect of different warning labels and endorsements on openness to trying alternative tobacco products

\begin{tabular}{|c|c|c|c|c|c|c|c|c|c|}
\hline & \multicolumn{3}{|c|}{ Moist snuff } & \multicolumn{3}{|c|}{ Snus } & \multicolumn{3}{|c|}{ E-cigarettes } \\
\hline & Pretest & Posttest & $d$ & Pretest & Posttest & $d$ & Pretest & Posttest & d \\
\hline Current WL & 1.12 & 1.88 & $0.38^{*}$ & 1.08 & 1.75 & $0.39^{*}$ & 1.12 & 1.72 & $0.37^{*}$ \\
\hline Graphic WL & 1.00 & 1.44 & $0.33^{*}$ & 1.03 & 1.34 & $0.29^{*}$ & 1.54 & 1.70 & 0.09 \\
\hline "Lower risks" & 1.12 & 1.31 & 0.19 & 1.14 & 1.33 & 0.18 & 1.40 & 2.18 & $0.38^{*}$ \\
\hline "FDA Approved" & 1.07 & 1.33 & $0.29^{*}$ & 1.15 & 1.47 & $0.26^{*}$ & 1.40 & 1.62 & 0.14 \\
\hline No Label & 1.10 & 1.35 & 0.20 & 1.05 & 1.55 & $0.36^{*}$ & 1.15 & 1.71 & $0.42^{*}$ \\
\hline Control Advertisement & 1.07 & 1.48 & $0.30^{*}$ & 1.05 & 1.33 & $0.24^{*}$ & 1.42 & 1.85 & $0.24^{*}$ \\
\hline
\end{tabular}

${ }^{*} p<.05$ (Significant differences from pretest to posttest, multivariate simple effects of time based on the linearly independent pairwise comparisons among the estimated marginal means). 
than smoking will encourage smokers who cannot quit to switch to less dangerous tobacco products and avoid the worst health consequences of cigarette smoking $[35,36]$. However, endorsing alternative tobacco products as less harmful might encourage initiation in youth or non-users, relapse in former smokers, or deter smokers from quitting, thus increasing harm to public health [37]. This study demonstrates that the "lower risk" warning label also leads to perceptions of lower risk among non-tobacco users. Even though participants in this study were non-smokers and non-users of smokeless tobacco, over $4 \%$ had tried one of the alternative tobacco products, most frequently e-cigarettes. Our data show that at least some non-smokers are trying and using e-cigarettes, and that interest in trying the products was higher among those non-users of tobacco who had lower perception of harm of these products. This study provides additional evidence suggesting the FDA should deny the R.J. Reynolds's petition to replace the current warning label with a warning label communicating lower risk of smokeless tobacco.

This is also the first study to investigate the effects of warning labels on perceptions of electronic cigarettes. Placing current warning label used on smokeless tobacco ("Warning: This product is not a safe alternative to cigarettes") or a graphic warning label on e-cigarette advertisements significantly increased perceived harm of e-cigarettes among non-users of tobacco products. It should be noted that perceived harm of e-cigarettes increased in all conditions (although not significantly) with the exception of when participants saw an e-cigarette advertisement without a warning label. In early 2014, the FDA proposed a "deeming rule" [38], extending its regulatory authority to other tobacco products, including electronic cigarettes. One of the provisions of this rule is to add the warning label to electronic cigarettes, "WARNING: This product contains nicotine derived from tobacco. Nicotine is an addictive chemical". (If the product contains no nicotine, the proposed warning label would state, "This product is derived from tobacco"). Based on our findings, it is likely that any warning label on electronic cigarettes would increase perceptions of risk among non-users of tobacco, and, as such, would be helpful in reducing population-level harm by reducing interest in the use of the products among non-users of tobacco.

Given the current lack of evidence about the longterm health effects of e-cigarettes, warning labels could also communicate the uncertainty about health effects of e-cigarettes; future studies should examine the effects of these types of warning labels on perceived harm.

It is worth noting that although participants were nonusers of tobacco (who had not smoked more than 100 cigarettes or used smokeless tobacco more than 20 times in their lifetime), almost 9\% reported trying alternative tobacco products and over $4 \%$ were current (past 30 days) users (those current users were excluded from the study). E-cigarettes were used the most frequently with 5.3\% reporting ever use and 3.4\% reporting past month use, followed by snus (ever use $2.8 \%$, past 30 days $1.0 \%$ ) and moist snuff (ever use 2.6\%, past 30 days 1.4\%). These e-cigarette trial numbers are higher than those reported previously. In 2010, $0.8 \%$ of never-smokers ever tried and $0.3 \%$ reported past month use of e-cigarettes [39]; another report indicated $1.2 \%$ ever use among never smokers [40]. It appears that as electronic cigarettes are becoming more visible in the society, more non-smokers may be trying and using them.

We also examined effects of warning labels on attitudes and behavioral intentions and found little effect of specific warning labels on those variables. The only significant change across all conditions and all three products was that participants who saw either the current warning label or the graphic warning label significantly decreased positive attitudes towards e-cigarettes. These significant changes occurred in the same conditions that exhibited significant increase in perceived harm of ecigarettes, suggesting that increase in perceived harm could possibly be responsible for decrease in positive attitudes towards e-cigarettes.

Openness to trying alternative tobacco products increased from pretest to posttest across every condition (significantly in over half the conditions) for all three products. Because the openness increased in every condition, even in control conditions where participants did not see advertisements for tobacco products, it is likely that this increase is an effect of a repeated testing. This finding is in line with a previous study (with a nationally representative sample of smokers) where openness to trying snus increased across all conditions [31]. It should also be noted that even with a slight increase in openness, participants predominantly remained "not at all open" at posttest, because the initial openness was so low, with most participants selecting the lowest possible option on the openness scale.

Although we did not measure actual behavior (e.g., tobacco use) in this study, we asked participants to select a free sample of the product and $14.9 \%$ of participants were interested in a free sample. There was no difference across the warning labels conditions, but overall, non-users of tobacco who wished to receive a free sample of alternative tobacco product held significantly lower perceptions of harm of these products than those who opted out of receiving free samples. Thus, perceived harm is related to potential behavior (trying the product), the finding that is in line with past research [10].

Recall for warning labels was different across the conditions, with highest recall for graphic warning labels. It should be noted that recall was only measured for the 
verbal portion - participants had to select among several textual warnings rather than indicate that they saw a graphic warning label. If we asked whether participant saw a graphic warning label, the recall might have been even higher. Low recall of "FDA Approved" label could be explained by the fact that people do not perceive it as 'warning.'

Limitations of this study include that it was a nonprobability-based sample; however, the sample was drawn from a diverse sample of non-users of tobacco in the United States with heterogeneous demographics. Our sample was more educated (with $58 \%$ of participants being college educated) as compared to the educational levels reported by the US census ( $29 \%$ of adult population in general, including tobacco users and non-users, being college educated) [41] and the 2012 NHIS (31\% of non-smokers being college-educated) [42]. Although we did have a sizable proportion of lower educated participants and education was not related to our main outcome variables, the characteristics of the sample might suggest the study results may limit the generalizability of the study to more educated populations.

Self-reported measures of perceived harm, attitudes, and openness to trying tobacco products might have been subject to social desirability bias, resulting in the high ratings of perceived harm and low attitudes and openness levels that we observed in this study, underestimating the effects of "lower risk" and "FDA Approved" labels. While the increase in perceived harm of alternative tobacco products was unambiguous for the current and graphic warning labels, the "lower risk" and "FDA Approved" label conditions showed weaker effects, so larger samples may be needed to obtain stable and more conclusive estimates of these smaller effects. Future studies should take these issues into account.

\section{Conclusions}

In conclusion, this study provides the first evidence against allowing "reduced harm" or "lower risk" labels on alternative tobacco products. While further data should be collected to validate our results, our findings provide initial evidence that endorsements such as the one proposed by RJ Reynolds may have similar effects to the prohibited "FDA Approved" label. Warning labels may be an effective way to decrease interest in e-cigarettes among non-users of tobacco. Regulatory agencies should consider implementing graphic warning labels for smokeless tobacco and investigate use of warning labels for e-cigarettes.

\section{Competing interests}

The authors declare that they have no competing interests.

\section{Authors' contributions}

LP designed the study, analyzed the data, and led the writing of the manuscript. PML obtained funding, and supervised the study conduct, data analysis and interpretation. Both authors contributed to the writing, revision, and approval of the final manuscript.

\section{Acknowledgements}

This work was funded by the National Cancer Institute (R01 CA-141661). The funders played no role in the design, in the collection, analysis, and interpretation of data, in the writing of the manuscript, or in the decision to submit the manuscript for publication. The article contents are solely the responsibility of the authors and do not necessarily represent the official views of the National Cancer Institute.

\section{Author details}

${ }^{1}$ Center for Tobacco Control Research and Education, University of California San Francisco, 530 Parnassus Avenue, Suite 366, San Francisco, CA 94143, USA. 2Division of General Internal Medicine, Department of Medicine, University of California San Francisco, San Francisco, USA.

Received: 18 June 2014 Accepted: 21 September 2014 Published: 25 September 2014

\section{References}

1. United States Department of Health and Human Services: The Health Consequences of Smoking - 50 Years of Progress: A Report of the Surgeon General. In Atlanta, GA: US Department of Health and Human Services, Center for Disease Control and Prevention, National Center for Chronic Disease Prevention and Health Promotion, Office of Smoking and Health; 2014.

2. Surgeon General's Advisory Committee on Smoking and Health: Smoking and Health; Report of the Advisory Committee to the Surgeon General of the Public Health Service. In Washington: U.S. Dept. of Health, Education, and Welfare, Public Health Service; 1964.

3. Romer D, Jamieson P: The Role Of Perceived Risk In Starting And Stopping Smoking. In Smoking: Risk, Perception, And Policy. Edited by Slovic P. Thousand Oaks, CA: Sage; 2001:65-80.

4. Song AV, Morrell HER, Cornell JL, Ramos ME, Biehl M, Kropp RY, Halpern-Felsher BL: Perceptions of smoking-related risks and benefits as predictors of adolescent smoking initiation. Am J Public Health 2009, 99(3):487-492.

5. Song AV, Glantz SA, Halpern-Felsher BL: Perceptions of Second-hand Smoke Risks Predict Future Adolescent Smoking Initiation. J Adolesc Health 2009, 45(6):618-625.

6. Hammond D, McDonald PW, Fong GT, Brown KS, Cameron R: The impact of cigarette warning labels and smoke-free bylaws on smoking cessation evidence from former smokers. Can J Public Health 2004, 95(3):201-204.

7. Hyland A, Li Q, Bauer JE, Giovino GA, Steger C, Cummings KM: Predictors of cessation in a cohort of current and former smokers followed over 13 years. Nicotine Tob Res 2004, 6(Suppl 3):S363-\$369.

8. Hammond D, Fong GT, McNeill A, Borland R, Cummings KM: Effectiveness of cigarette warning labels in informing smokers about the risks of smoking: findings from the International Tobacco Control (ITC) Four Country Survey. Tob Control 2006, 15 Suppl 3:iii19-iii25.

9. Canadian Cancer Society: Cigarette Package Health Warnings: International Status Report. In 3rd edition. ; 2012.

10. Hammond D, Fong GT, McDonald PW, Cameron R, Brown KS: Impact of the graphic Canadian warning labels on adult smoking behaviour. Tob Control 2003, 12(4):391-395.

11. Borland R: Tobacco health warnings and smoking-related cognitions and behaviours. Addiction 1997, 92(11):1427-1435.

12. World Health Organization Framework Convention on Tobacco Control: Elaboration of Guidelines for Implementation of Article 11 of the Convention. In 2008.

13. European Parliament and Council of the European Union: Directive 2014/ 40/EU of the European Parliament and of the Council of 3 April 2014 on the approximation of the laws, regulations and administrative provisions of the Member States concerning the manufacture, presentation and sale of tobacco and related products and repealing Directive 2001/37/ EC. Off J Eur Union 2014.

14. Mejia AB, Ling PM: Tobacco industry consumer research on smokeless tobacco users and product development. Am J Public Health 2010, 100(1):78-87.

15. Marketing Smokeless Tobacco: Moist Snuff, Snus, Dissolvables. http://trinketsandtrash.org/tt-feature/pdf/currrent_feature.pdf.

16. Curry LE, Pederson LL, Stryker JE: The changing marketing of smokeless tobacco in magazine advertisements. Nicotine Tob Res 2011, 13(7):540-547. 
17. Timberlake DS, Pechmann C, Tran SY, Au V: A content analysis of Camel Snus advertisements in print media. Nicotine Tob Res 2011, 13(6):431-439.

18. Osterdahl BG, Jansson C, Paccou A: Decreased levels of tobacco-specific $\mathrm{N}$-nitrosamines in moist snuff on the Swedish market. J Agric Food Chem 2004, 52(16):5085-5088.

19. Callery WE, Hammond D, O'Connor RJ, Fong GT: The appeal of smokeless tobacco products among young Canadian smokers: the impact of pictorial health warnings and relative risk messages. Nicotine Tob Res 2011, 13(5):373-383.

20. Grana RA, Ling PM: "Smoking Revolution": a content analysis of electronic cigarette retail websites. Natl Inst Health State Sci Statement Tob Use Prev Cessation Control 2014, 46(4):395-403

21. Benowitz NL, Goniewicz ML: The regulatory challenge of electronic cigarettes. JAMA 2013, 310(7):685-686.

22. Cobb NK, Byron MJ, Abrams DB, Shields PG: Novel nicotine delivery systems and public health: the rise of the "e-cigarette". Am J Public Health 2010, 100(12):2340-2342.

23. United States Department of Health and Human Services: Preventing Tobacco Use Among Youth and Young Adults: A Report of the Surgeon General. In Atlanta, GA: Department of Health and Human Services, Centers for Disease Control and Prevention, National Center for Chronic Disease Prevention and Health Promotion, Office on Smoking and Health; 2012.

24. Reynolds RJ: Citizen Petition. 2011, http://www.regulations.gov/\#! documentDetail:D=FDA-2011-P-0573-0001.

25. Paradise Vape. http://www.paradisevape.net/.

26. 21st Century Smoke. http://www.21stcenturysmoke.com/product-p/37-515cr.htm

27. Q Vapor Labs inc. http://qvapour.com/legal/.

28. Counterfeit FDA seal on e-cigarette 'juice'. http://www.news4jax.com/ news/counterfeit-fda-seal-on-ecigarette-juice/26355186.

29. 15 U.S.C. $\$ 4402(b)(2) .2012$

30. Hammond D, Doxey J, Daniel S, Bansal-Travers M: Impact of female-oriented cigarette packaging in the United States. Nicotine Tob Res 2011, 13(7):579-588.

31. Popova L, Neilands TB, Ling PM: Testing messages to reduce smokers' openness to using novel smokeless tobacco products. Tob Control 2014 23(4):313-321.

32. Ruxton GD: The unequal variance $t$-test is an underused alternative to Student's t-test and the Mann-Whitney U test. Behav Ecol 2006, 17(4):688-690.

33. McDaniel PA, Malone RE: Understanding Philip Morris's pursuit of US government regulation of tobacco. Tob Control 2005, 14(3):193-200.

34. Philip Morris: Societal Alignment. In 2000. Bates No. 2505614860/4879.

35. Rodu B, Godshall WT: Tobacco harm reduction: an alternative cessation strategy for inveterate smokers. Harm Reduct J 2006, 3:37.

36. Britton J: Should doctors advocate snus and other nicotine replacements? Yes. BMJ 2008, 336(7640):358.

37. Mejia $A B$, Ling PM, Glantz $S A$ : Quantifying the effects of promoting smokeless tobacco as a harm reduction strategy in the USA. Tob Control 2010, 19(4):297-305.

38. Department of Health and Human Services: Food and Drug Administration: Deeming Tobacco Products To Be Subject to the Federal Food, Drug, and Cosmetic Act, as Amended by the Family Smoking Prevention and Tobacco Control Act; Regulations on the Sale and Distribution of Tobacco Products and Required Warning Statements for Tobacco Products; Proposed Rule (21 CFR Parts 1100, 1140, and 1143). Fed. Reg 2014, 79:23142-23207.

39. Pearson JL, Richardson A, Niaura RS, Vallone DM, Abrams DB: e-Cigarette awareness, use, and harm perceptions in US adults. Am J Public Health 2012, 102(9):1758-1766.

40. King BA, Alam S, Promoff G, Arrazola R, Dube SR: Awareness and ever-use of electronic cigarettes among US adults, 2010-2011. Nicotine Tob Res 2013, 15(9):1623-1627

41. U.S. Census Bureau: Current Population Survey, 2013 Annual Social and Economic Supplement. In 2013.

42. National Center for Health Statistics: National Health Interview Survey In 2012. Retrieved from http://www.cdc.gov/nchs/nhis.htm.

doi:10.1186/1471-2458-14-997

Cite this article as: Popova and Ling: Nonsmokers' responses to new warning labels on smokeless tobacco and electronic cigarettes: an experimental study. BMC Public Health 2014 14:997.

\section{Submit your next manuscript to BioMed Central and take full advantage of:}

- Convenient online submission

- Thorough peer review

- No space constraints or color figure charges

- Immediate publication on acceptance

- Inclusion in PubMed, CAS, Scopus and Google Scholar

- Research which is freely available for redistribution 